ORIGINAL ARTICLE

\title{
Cooling methods used in the treatment of exertional heat illness
}

\section{J E Smith}

Br J Sports Med 2005;39:503-507. doi: 10.1136/bjsm.2004.013466

Correspondence to:
Dr Smith, Emergency
Department, Derriford
Hospital, 4 Fort Terrace,
Plymouth PL6 5BU, UK;
jasonesmith@doctors.
org.uk
Accepted
27 September 2004

....................

\begin{abstract}
Objective: To review the different methods of reducing body core temperature in patients with exertional heatstroke.

Methods: The search strategy included articles from 1966 to July 2003 using the databases Medline and Premedline, Embase, Evidence Based Medicine (EBM) reviews, SPORTDiscus, and cross referencing the bibliographies of relevant papers. Studies were included if they contained original data on cooling times or cooling rates in patients with heat illness or normal subjects who were subjected to heat stress.

Results: In total, 17 papers were included in the analysis. From the evidence currently available, the most effective method of reducing body core temperature appears to be immersion in iced water, although the practicalities of this treatment may limit its use. Other methods include both evaporative and invasive techniques, and the use of chemical agents such as dantrolene.

Conclusions: The main predictor of outcome in exertional heatstroke is the duration and degree of hyperthermia. Where possible, patients should be cooled using iced water immersion, but, if this is not possible, a combination of other techniques may be used to facilitate rapid cooling. There is no evidence to support the use of dantrolene in these patients. Further work should include a randomised trial comparing immersion and evaporative therapy in heatstroke patients.
\end{abstract}

$\mathrm{H}$ eat illness is an unchecked increase in body core temperature that occurs when intrinsic or extrinsic heat generation overwhelms homoeostatic thermoregulation. Consequential dysfunction at cellular and organ level results in a spectrum of disease from minor heat cramps through symptoms of heat exhaustion to life threatening heatstroke. ${ }^{1}$ Heatstroke is characterised by neurological disturbance associated with haematological abnormalities, and may result in multiorgan failure and death. ${ }^{2}$

Classical or environmental heat illness occurs in those whose thermoregulatory control mechanisms are inefficient, such as the very young or elderly, and those subjected to extreme temperatures. The main factor in the development of this condition is a high environmental temperature, with clusters of cases occurring after heat waves (700 heat related deaths were reported after the Chicago heat wave of 1995) $)^{3}$ and the annual pilgrimages in the Middle East.

In contrast, exertional heat illness typically affects young athletes or military personnel, who are pushed to their physical limits and suffer a clinical and pathological syndrome caused by an inability to dissipate heat produced by muscular exercise. This can occur at any time of year, and is a reflection of intrinsic heat production rather than external heat. There are usually identifiable risk factors such as dehydration, concurrent illness, lack of sleep, obesity, alcohol ingestion, wearing too much clothing, or poor cardiovascular fitness. ${ }^{145}$ However, sometimes no precipitating factors are evident, and the reason why one individual is affected by heatstroke while others remain unaffected is not clearly understood.

Despite differences in their pathophysiology, the recommended treatment of these conditions is similar. An assessment of airway, breathing, and circulation should be the priority, and basic life support instituted if appropriate. High flow oxygen should be administered, intravenous access achieved, and initial observations should include a rectal temperature. Subsequently the emphasis is placed on reduction of core temperature as quickly as possible, as it has been suggested that the major determinant of outcome in heatstroke is the duration of hyperthermia. One case series found a trend towards improved survival in patients cooled to a core temperature below $38.9^{\circ} \mathrm{C}$ within 60 minutes, ${ }^{6}$ and another report found improved survival when patients were cooled to the same level within 30 minutes, although the methods of cooling are not explored in detail in this paper. ${ }^{3}$ The evidence is limited, but what little there is would suggest that outcome may be improved when core temperature is reduced as quickly as possible. This remains the cornerstone of treatment of heatstroke patients, and is emphasised in the Inter-Association Task Force on Exertional Heat Illness consensus statement.?

Several methods of body cooling have been described, as outlined in box 1. The evidence to support one method over the other is limited and appears contradictory, and authors have proposed there is no evidence one way or the other. ${ }^{1}$ The aim of this review is therefore to examine and appraise this evidence, and give a summary and recommendations based on its findings.

\section{METHODS}

A comprehensive search of the literature was carried out, using Medline and Premedline 1966 to July 2003, Embase, Evidence Based Medicine (EBM) reviews (including the Cochrane database of systematic reviews and the Cochrane central register of controlled trials), and the SPORTDiscus database. Search terms included heat stress disorders, heat stroke, heatstroke, heat exhaustion, heat illness, and heat injury. Papers were included if they contained original data on cooling times or cooling rates in patients with heat illness, or normal subjects who were subjected to heat stress. Owing to the lack of evidence on the treatment of patients with exertional heat illness in particular, papers describing the treatment of patients with classical or environmental heat illness were also examined. The bibliographies of relevant papers were examined and cross referenced. Papers were critically appraised for the quality of evidence presented. The 


\section{Box 1: Methods of body cooling}

- Body immersion in iced water

- Evaporative cooling: spraying water over the patient and facilitating evaporation and convection with the use of fans

- Immersing the hands and forearms in cold water

- Use of ice or cold packs in the neck, groins, and axillae

- Invasive methods: iced gastric, bladder, or peritoneal lavage

- Chemically assisted cooling with dantrolene

criteria used were relevance to the question asked and study design. Studies were preferred in accordance with the usual hierarchy of evidence, namely controlled clinical trials, prospective studies (including case control studies), and case reports. ${ }^{8}$ Review articles were examined for their reference lists.

\section{SEARCH RESULTS}

Two controlled trials comparing cooling methods (one randomised ${ }^{9}$ and one non-randomised $\operatorname{comparison}^{10}$ ), and two randomised controlled trials ${ }^{11}{ }^{12}$ investigating the use of dantrolene in the treatment of heat illness were found, and these are examined in detail in table 1 . Several case series ${ }^{6}{ }^{13-19}$ and experimental models using healthy volunteers ${ }^{20-24}$ were also found, and these are summarised in table 2. In total 17 papers were used in the analysis.

\section{Immersion}

In some centres immersion in iced water is the preferred method of cooling, including the US Marine Corps training base at Parris Island, ${ }^{25}$ although this may not be optimal treatment for patients with a reduced level of consciousness, and, for those who are alert, it is uncomfortable and often intolerable. However, the best cooling times and rates for treatment of heat illness patients were achieved using this technique.

In a non-randomised study, a comparison was made of iced water immersion and placing wet towels over the torso, ${ }^{10}$ showing that iced water immersion cooled patients faster than the wet towels, with a cooling rate of $0.20^{\circ} \mathrm{C} / \mathrm{min}$ for iced water and $0.11^{\circ} \mathrm{C} / \mathrm{min}$ for wet towels. However, the study design allowed clinicians to choose which patients received which treatment, a source of considerable selection bias. It also compared two similar forms of cooling, rather than comparing immersion with evaporative techniques.

In a case series of 28 classical heatstroke patients, immersion in iced water enabled cooling to less than $102^{\circ} \mathrm{F}$ $\left(38.9^{\circ} \mathrm{C}\right)$ in less than 45 minutes in all patients. ${ }^{14}$ Of note, some of the patients in this study could not tolerate being immersed and were massaged with ice instead. These patients were not analysed separately, and the relative importance of the ice massage cannot therefore be elucidated. In another case series of 27 patients with exertional heatstroke or heat exhaustion, all were cooled by iced water immersion, achieving a mean cooling time (to $\mathrm{T}_{\mathrm{re}}<39^{\circ} \mathrm{C}$ ) of 19.2 minutes, with a cooling rate of $0.15^{\circ} \mathrm{C} / \mathrm{min}^{18}$

Supporters of other cooling methods suggest that iced water immersion may cause peripheral vasoconstriction and therefore slow cooling, although this has never been proven experimentally. Indeed, a recent study using normal volunteers has shown that cooling rates were fastest when the coldest water was used..$^{25 a}$

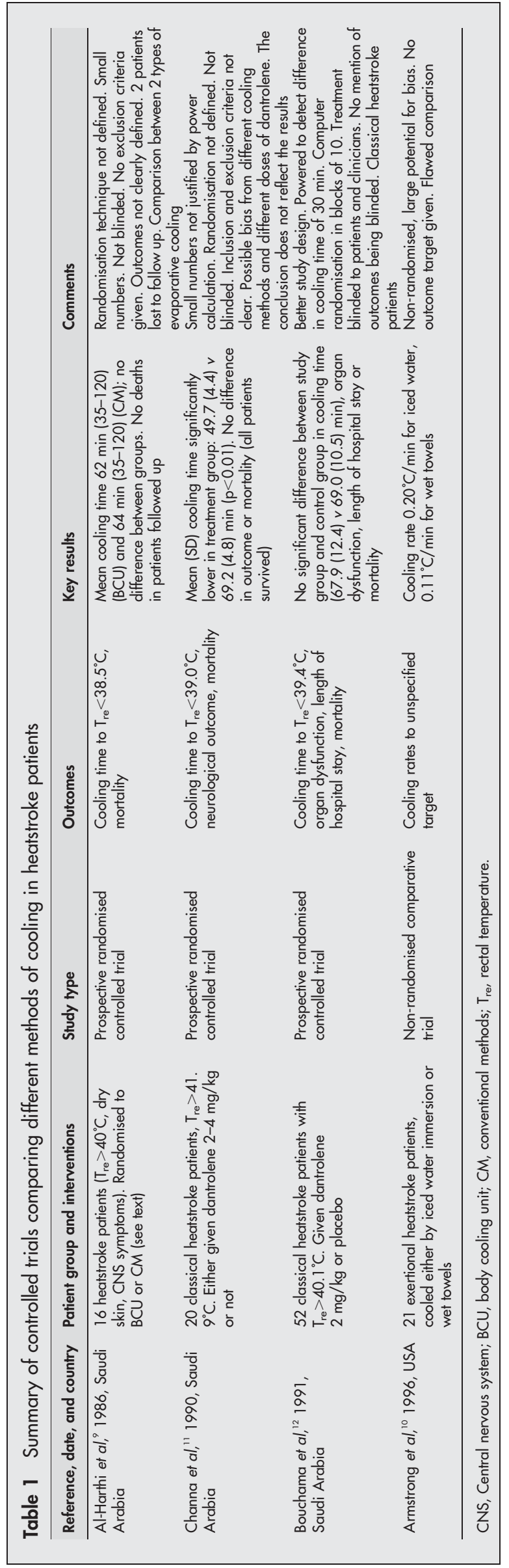




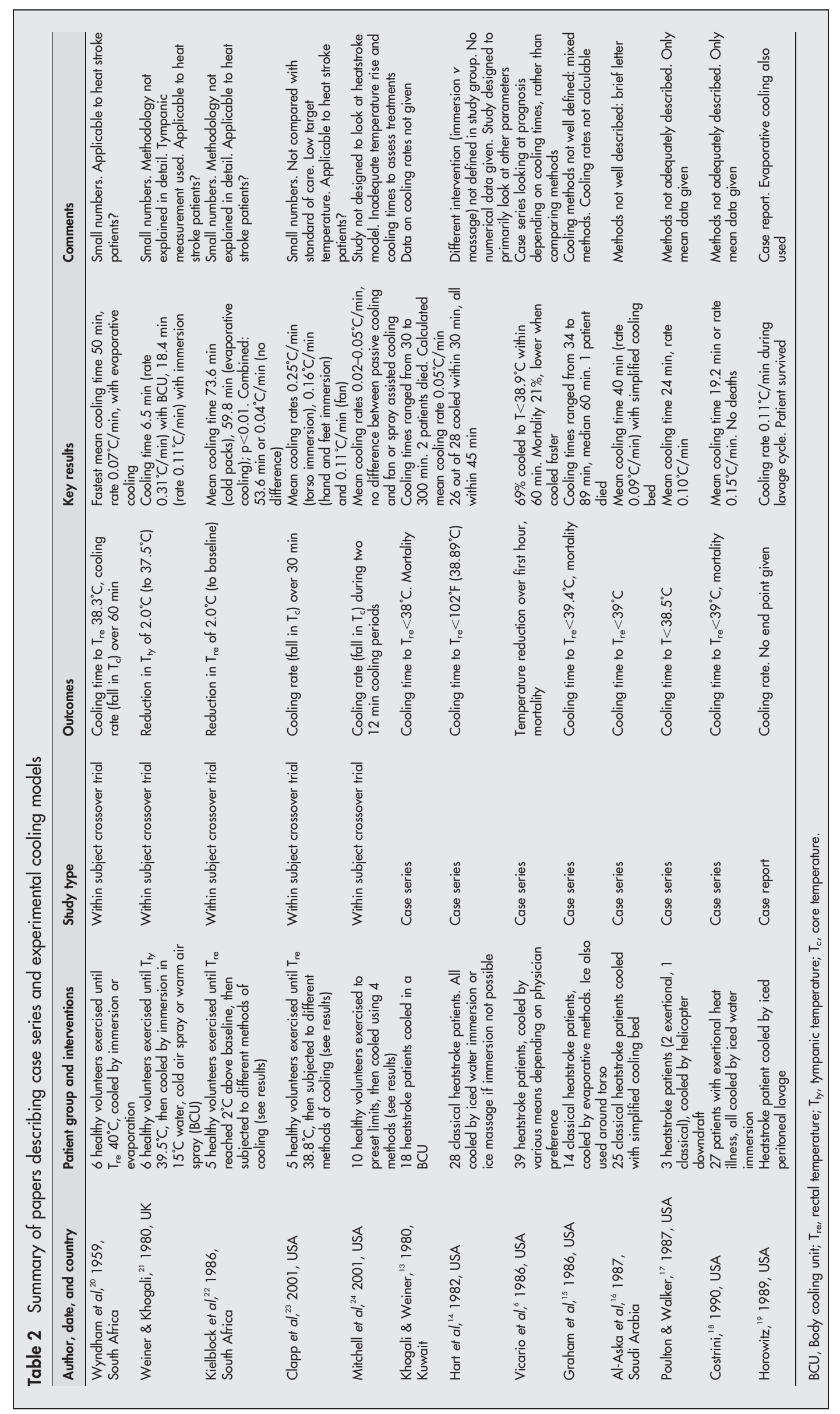




\section{Evaporative methods}

Evaporative cooling involves the removal of clothing, spraying tepid water over the patient, and facilitating evaporation and convection with the use of a fan. This was shown in the first published study of its kind to be better than other methods of cooling in normal volunteers. ${ }^{20}$ The basic idea was modified into a more sophisticated model termed a body cooling unit, involving water sprayed at $15^{\circ} \mathrm{C}$ being mixed with warm air flow to maintain skin temperature at 32 $33^{\circ} \mathrm{C}^{13}{ }^{21}$ Theoretical advantages of this include reducing peripheral vasoconstriction and thereby allowing heat to be lost more effectively. In a randomised controlled trial of classical heatstroke patients, the body cooling unit was compared with conventional methods of cooling (covering the patient in a wet sheet, spraying tap water on to the sheet, and using fans to blow air over the patient), but no difference in cooling time was found. ${ }^{9}$ This comparison was also flawed, in that it compared two very similar methods of cooling with no reference made to iced water immersion therapy.

In another study, the body cooling unit was shown to be better than other methods of cooling in normal volunteers, ${ }^{21}$ achieving rapid cooling with a mean rate of $0.31{ }^{\circ} \mathrm{C} / \mathrm{min}$, but in a case series of 18 heatstroke patients achieved a mean cooling rate of only $0.05^{\circ} \mathrm{C} / \mathrm{min}$, with cooling times (to $\mathrm{T}_{\mathrm{re}}<39^{\circ} \mathrm{C}$ ) ranging from 30 to 300 minutes..$^{13}$ In another case series, a simplified cooling bed achieved slightly better results, with a mean cooling time of 40 minutes (rate $0.09^{\circ} \mathrm{C} / \mathrm{min}$ ). ${ }^{16}$

\section{Other cooling methods}

Immersing the hands and forearms in cold water results in reduction of heat stress in normal subjects, ${ }^{26-28}$ but has not been evaluated in the treatment of heatstroke patients. The placement of ice packs in the axillae, groin, and neck has been recommended as an easy method to use in the field, ${ }^{29} 30$ but when compared with evaporative cooling in five healthy subjects, cooling times were longest when the ice packs were used alone and shortest when both methods were used simultaneously. ${ }^{22}$ Another method of evaporative cooling has been described using the downdraft of a helicopter, which was reported to have better results than using the body cooling unit, although this case series only involved three patients (mean cooling time to $\mathrm{T}_{\mathrm{re}}<38.5^{\circ} \mathrm{C} 24$ minutes, rate $0.10^{\circ} \mathrm{C} / \mathrm{min}$ ), and the method is clearly not generally available. ${ }^{17}$ Invasive methods of cooling include gastric, peritoneal, and bladder lavage with cold water. These have been investigated in animal models, ${ }^{31-33}$ but the only data in human subjects come from a case series where gastric lavage is described, ${ }^{6}$ and a single case report, when cooling was achieved in a patient resistant to evaporative techniques. ${ }^{19}$ The role of invasive cooling methods has therefore not been fully established.

\section{Dantrolene}

Dantrolene is an agent that impairs calcium release from the sarcoplasmic reticulum and by doing so reduces muscle excitation and contraction. It is used in the treatment of malignant hyperthermia and neuroleptic malignant syndrome, reducing heat production that occurs as a result of muscle rigidity or hypertonicity typical of these conditions. ${ }^{34}$ It has been suggested that similar pathophysiological mechanisms underlie heat illness, and dantrolene has been proposed as a possible means to reduce core temperature in this condition. ${ }^{35-40}$ The search strategy for this review yielded two randomised trials ${ }^{11}{ }^{12}$ as shown in table 1 .

In the first trial, 20 heatstroke patients were randomised either to receive dantrolene $2-4 \mathrm{mg} / \mathrm{kg}$ (study group) or not (control group). ${ }^{11}$ Patients were externally cooled using either a body cooling unit or conventional evaporative methods, although which patients received which method is not defined. The results showed a significantly shorter cooling time $\left(\mathrm{T}_{\mathrm{re}}<39.0^{\circ} \mathrm{C}\right)$ in the study group $(49.7$ (4.4) $v 69.2$ (4.8) minutes, $\mathrm{p}<0.01$ ), but no difference in outcome between the two groups. Table 1 outlines the methodological flaws in this study, which should induce caution in the interpretation of its results. In the second trial, 52 classical heatstroke patients were randomised to receive either dantrolene $2 \mathrm{mg} / \mathrm{kg}$ or placebo (normal saline). ${ }^{12}$ All patients were externally cooled using a body cooling unit, and rectal temperature was continuously recorded to determine cooling time (time to reach $\mathrm{T}_{\mathrm{re}}<39.0^{\circ} \mathrm{C}$ ). The results showed no difference in cooling times between groups (treatment group 67.9 (12.4) minutes $v$ control group 69.0 (10.5) minutes), and no difference in complications, length of stay, or mortality (one patient died in the control group). From this well designed trial, the authors conclude that, at the dose given, dantrolene has no additional benefit over traditional external cooling methods.

\section{DISCUSSION}

As is evident from this collection of the available data, there is conflicting evidence as to the best form of cooling in heatstroke patients. Treatment should start with an assessment of airway, breathing, and circulation, and measurement of rectal temperature. According to the best evidence currently available, it would appear that immersion in iced water is the most effective method of whole body cooling, and should be used where possible. However, it may not be practical from a logistic or clinical perspective, and treatment may have to be tailored to the clinical situation. For patients with a reduced level of consciousness, it may prove hazardous and is not recommended unless specific facilities allowing continued intensive medical care are available.

If immersion is unavailable or inappropriate, cooling may necessarily involve a combination of evaporative cooling techniques and other methods such as immersion of the extremities in cold water. At the roadside of an endurance event, this may be the most appropriate method of cooling. Future work should include a prospective randomised trial comparing iced water immersion with evaporative techniques in exertional heat illness patients to clarify the optimal method.

There is no clear evidence to support the use of dantrolene in the treatment of exertional heatstroke, and the priority, after an assessment of airway, breathing, and circulation, should be to institute external cooling methods to reduce core temperature as quickly as possible. Other suggested treatments such as the use of antipyretics and immunomodulatory agents have not yet been evaluated in human subjects.

This review was essentially limited to human studies, and data from animal studies have not been included. It may be subject to publication bias, and has included papers from predominantly English Language journals. The distinction has been drawn between those papers describing cooling in heatstroke patients and those involving normal volunteers exposed to experimental conditions. It should be stressed that experiments in which cooling rates are measured in normal subjects who have been exercising have limited applicability to treating heatstroke patients whose thermoregulation mechanisms have failed. The treatment of classical heat illness patients has also been included, although whether this can be extrapolated to patients with exertional heat illness is not clear.

Comparison of papers was made more difficult by the different outcome measures used by different groups, but where possible cooling times and rates have been extracted and compared. The lack of robust evidence highlights the requirement for a large, well designed, randomised controlled trial comparing iced water immersion with evaporative techniques for the treatment of heatstroke. 


\section{What is already known on this topic}

- Classical or environmental heat illness results from inefficient thermoregulatory control mechanisms in those subjected to extreme temperatures.

- Exertional heat illness results from an inability to dissipate heat produced by muscular exercise.

- The recommended treatment of these conditions is similar: assessment of airway, breathing, and circulation and basic life support, followed by reduction of core temperature as quickly as possible.

- Several methods of body cooling have been recommended.

\section{What this study adds}

- The main predictor of outcome in exertional heatstroke is the duration and degree of hyperthermia.

- Patients should be cooled using iced water immersion, but, if this is not possible, a combination of other techniques may be used.

- There is no evidence to support the use of dantrolene in these patients.

- Further work should include a randomised trial comparing immersion and evaporative therapy in heatstroke patients.

\section{CONCLUSIONS}

The treatment of exertional heatstroke should begin with an assessment of airway, breathing, and circulation, and initiation of resuscitation if necessary. Subsequently whole body cooling should be the priority. Where possible, patients should be cooled using iced water immersion, although this may not always be practical and a combination of other techniques may be needed to facilitate rapid cooling. There is no evidence to support the use of dantrolene in these patients.

Competing interests: none declared

\section{REFERENCES}

1 Bouchama A, Knochel JP. Heat stroke. New Engl J Med 2002;346:1978-88.

2 Epstein Y, Moran DS, Shapiro Y, et al. Exertional heat stroke: a case series. Med Sci Sports Exerc 1999;31:224-8.

3 Dematte JE, O'Mara K, Buescher J, et al. Near-fatal heat stroke during the 1995 heat wave in Chicago. Ann Intern Med 1998;129:173-81.

4 Chung NK, Pin CH. Obesity and the occurrence of heat disorders. Mil Med 1996;161:739-42.

5 Gardner JW, Kark JA, Karnel K, et al. Risk factors predicting exertional heat illness in male Marine Corps recruits. Med Sci Sport Exerc 1996;28:939-44.

6 Vicario SJ, Okabajue R, Haltom T. Rapid cooling in classic heatstroke: effect on mortality rates. Am J Emerg Med 1986;4:394

7 Inter-Association Task Force on Exertional Heat Illness. Consensus statement 2002. http://www.acsm.org/publications/pdf/HeatlllnessConsensusStmt.pdf (accessed 28 Jul 2004).

8 Oxford Centre for Evidence-based Medicine. Levels of evidence. http:// www.cebm.net/levels_of_evidence.asp (accessed 28 Jul 2004).

9 Al-Harthi SS, Yaqub BA, Al-Nozha MM, et al. Management of heat stroke patients by rapid cooling at Mecca pilgrimage. Saudi Med J 1986;7:369.

10 Armstrong $L E$, Crago $A E$, Adams $R$, et al. Whole-body cooling of hyperthermic runners: comparison of two field therapies. Am J Emerg Med 1996; 14:355-8.

11 Channa AB, Seraj MA, Saddique AA, et al. Is dantrolene effective in heat stroke patients? Crit Care Med 1990;18:290-2.

12 Bouchama A, Cafege A, Devol EB, et al. Ineffectiveness of dantrolene sodium in the treatment of heatstroke. Crit Care Med 1991;19:176-80.

13 Khogali M, Weiner JS. Heat stroke: report of 18 cases. Lancet 1980;ii:276-8.
14 Hart GR, Anderson RJ, Crumpler CP, et al. Epidemic classical heatstroke: clinical characteristics and course of 28 patients. Medicine 1981;61:189.

15 Graham BS, Lichtenstein MJ, Hinson JM, et al. Nonexertional heatstroke. Arch Intern Med 1986;146:87-90.

16 Al-Aska A, Abu-Aisha H, Yaqub B, et al. Simplified cooling bed for heat stroke. Lancet 1987;i:381.

17 Poulton TJ, Walker RA. Helicopter cooling of heatstroke victims. Aviat Space Environ Med 1987;58:358-61.

18 Costrini A. Emergency treatment of exertional heatstroke and comparison of whole body cooling techniques. Med Sci Sport Exerc 1990;22:15-18.

19 Horowitz BZ. The golden hour in heat stroke: use of iced peritoneal lavage. Am J Emerg Med 1989;7:616-19.

20 Wyndham CH, Strydom NB, Cooke HM, et al. Methods of cooling subjects with hyperpyrexia. J Appl Physiol 1959:14:771-6.

21 Weiner JS, Khogali M. A physiological body cooling unit for treatment of heat stroke. Lancet 1980;i:507.

22 Kielblock AJ, Van Rensburg JP, Franz RM. Body cooling as a method for reducing hyperthermia. An evaluation of techniques. S Afr Med J 1986:9:378-80.

23 Clapp AJ, Bishop PA, Muir I, et al. Rapid cooling techniques in joggers experiencing heat strain. J Sci Med Sport 2001;4:160-7.

24 Mitchell JB, Schiller ER, Miller JR, et al. The influence of different externa cooling methods on thermoregulatory responses before and after intense intermittent exercise in the heat. J Strength Cond Res 2001;15:247-54.

25 Gaffin SL, Gardner JW, Flinn SD. Cooling methods for heatstroke victims. Ann Intern Med 2000; 132:678.

25a Proulx Cl, Ducharme MB, Kenny GP. Effect of water temperature on cooling efficiency during hyperthermia in humans. J Appl Physiol 2003:94:1317-23.

26 Livingstone SD, Nolan RW, Cattroll SW. Heat loss caused by immersing the hands in water. Aviat Space Environ Med 1989;60:1 166-71.

27 Allsopp AJ, Poole K. The effect of hand immersion on body temperature when wearing impermeable clothing. J R Nav Med Serv 1991;77:41-7

28 House JR, Holmes C, Allsopp AJ. Prevention of heat strain by immersing the hands and forearms in water. J R Nav Med Serv 1997;83:26-30.

29 Richards D, Richards R, Schofield PJ, et al. Management of heat exhaustion in Sydney's the sun city to surf fun runners. Med J Aust 1979;2:457-61.

30 Roberts WO. Managing heatstroke: on-site cooling. Phys Sportsmed 1992;20:17-28.

31 Bynum G, Patton J, Bowers W, et al. Peritoneal lavage cooling in an anaesthetized dog heatstroke model. Aviat Space Environ Med 1978;49:779-84

32 Syverud SA, Barker WJ, Amsterdam JT, et al. Iced gastric lavage for treatment of heatstroke: efficacy in a canine model. Ann Emerg Med 1985;14:424-32.

33 White JD, Riccobene E, Nucci R, et al. Evaporation versus iced gastric lavage treatment of heatstroke: comparative efficacy in a canine model. Crit Care Med 1987; 15:748-50.

34 Ward A, Chaffman MO, Sorkin EM. Dantrolene. A review of its pharmacodynamic and pharmacokinetic properties and therapeutic use in malignant hyperthermia, the neuroleptic malignant syndrome and an update of its use in muscle spasticity. Drugs 1986;32:130-68.

35 Denborough MA. Heat stroke and malignant hyperpyrexia. Med J Aust 1982;1:204-5.

36 Denborough MA. Fatal thermal injury. Med J Aust 1989;150:608

37 Larner AJ. Dantrolene for exertional heatstroke. Lancet 1992;339:182.

38 Lydiatt JS, Hill GE. Treatment of heat stroke with dantrolene. JAMA 1981;246:41-2.

39 Paasuke RT. Drugs, heatstroke and dantrolene. Can Med Assoc J 1984;130:341-2

40 Knochel JP. Treatment of heat stroke. JAMA 1983;249:1006-7.

The author's review of the management of exertional heat illness clearly highlights the problem in deciding the best treatment for this group of patients, who are typically young and healthy but who have a high mortality and morbidity, related directly to the duration of the temperature rise.

With regard to the best form of treatment, there are two camps, equally split between immersion and evaporative therapy. The evidence presented here appears to support the use of immersion in ice water, while acknowledging the limitations both in terms of the quality of evidence available and the practicalities of using this technique.

This is yet another area of sports medicine in which the answer to a seemingly simple question is still unknown, and presents an area in need of a well conducted randomised trial.

L Wallis

University of Cape Town, PO Box 901, Wellington 7654, South Africa; leewallis@bvr.co.za 